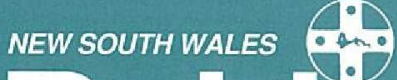 Public

\section{TUBERCULOSIS CONTROL: THE CHALLENGE CONTINUES}

\section{GUEST EDITORIAL}

Jeremy McAnulty and Peter Massey ${ }^{2}$

1. Medical Epidemiologist, AIDS / Infectious Diseases Branch and Chair of the NSW Tuberculosis Advisory Committee.

2. Public Health Nurse, New England Area Health Service and Acting NSW

Tuberculosis Coordinator.

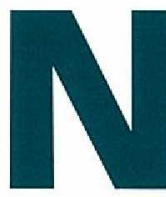

ot very long ago in the history of public health in NSW tuberculosis was a major killer. In 1935 the NSW Department of Public Health recorded 1,572 cases of pulmonary tuberculosis, including 939 deaths - rates of 59/100,000 and $35 / 100,000$ respectively. After World War II the development of effective therapy, contact tracing, screening, and a strong network of chest clinics throughout the State led to the control of TB and a dramatic decline in incidence. Today NSW has one of the lowest rates of TB in the world; there were 260 notifications of pulmonary tuberculosis in $1995^{1}$ (a rate of $4.2 / 100,000$ ) in NSW, and around 0.5 deaths per 100,000 in Australia as a whole ${ }^{2}$.

These rates could be lower, however, and the prevention and control of TB continues to be a high priority in NSW. Tuberculosis Coordinators in each of the State's 17 Area Health Services are responsible for coordinating TB surveillance, treatment, case investigation, contact screening and preventive therapy, which are carried out by nursing staff and physicians in a network of chest clinics. These clinics rely heavily on the expertise of local and referral laboratory services, and the cooperation of family doctors in referring patients and facilitating ongoing care. At the State level, the Tuberculosis Advisory Committee (TBAC), the membership of which includes physicians, nurses and epidemiologists, makes policy recommendations, drawing on data collected in the field by chest clinic staff, the medical literature and overseas guidelines. Recent issues considered by TBAC have included control of TB in prisons, prevention of the spread of TB from infectious passengers on airline flights, the use of prophylactic rifabutin, supply of drugs for TB management, new technologies for drug testing, use of BCG vaccine among health care workers, screening of refugees for $\mathrm{TB}$, and improved TB surveillance. These and other emerging issues, such as tuberculosis-HIV co-infection, and multi-drug-resistant organisms, present continuing challenges.

In this issue of the Public Health Bulletin, we examine the epidemiology of tuberculosis in NSW in 1995 with Heath et al; hear from an old friend, Dr Michael Levy (the Department's former specialist medical adviser on infectious diseases, now with the World Health Organization); get an update on an investigation from Conaty et al about the emerging risk of tuberculosis in prisons; and have a round-up of TB control activities in recent years from the Public Health Network. As these articles highlight, continued vigilance is essential for sustained TB control. Tuberculosis is a disease with a long history, and it has very real implications for today.

1. Heath T, Winks M, Roberts C, Capon A. Tuberculosis in NSW: Status and priorities. NSW Public Health Bulletin 1996;7(11):135-137.

2. Oliver G. Tuberculosis notifications in Australia, 1994. Comm Dis Intell 1996; 20:108-115.

\section{Contents}

\section{Articles}

131 Tuberculosis control:

The challenge continues

- Guest editorial

132 Public Health Network

Report: Tuberculosis

134 Tuberculosis in 1996:

A view from Geneva

135 Tuberculosis in NSW:

Status and priorities

138 Tuberculosis in NSW

Correctional Centres:

Disease control measures

following infectious cases

140 Infectious Diseases

\section{Correspondence}

Please address all correspondence and potential contributions to:

\section{The Editor,}

NSW Public Health Bulletin, Public Health Division, NSW Health Department Locked Bag No 961 , North Sydney NSW 2059 Telephone: (O2) 93919191

Facsimile: (02) 93919029 